\title{
A extensão universitária na Famed/UFRGS: cenário de formação profissional
}

\author{
Academic extension activities at the UFRGS School \\ of Medicine: a professional training scenario
}

Cynthia Isabel Ramos Vivas Ponte ${ }^{\mathrm{I}}$

Marco Antonio Rodrigues Torres ${ }^{I}$

Carmen Lucia Bezerra Machado ${ }^{\mathrm{I}}$

Waldomiro Carlos Manfrói ${ }^{\mathrm{I}}$

\author{
PALAVRAS-CHAVE \\ - Educação médica \\ - Relações Comunidade-Instituição \\ - Educação Profissionalizante \\ - Pesquisa
}

Recebido em: 02/06/2008

Reencaminhado em: 18/12/2008

Reencaminhado em: 18/03/2009

Aprovado em: 01/04/2009

\section{A B S T R A C T}

This study aimed to develop and apply a research methodology allowing the analysis of extension activities by faculty members from the School of Medicine of the Federal University in Rio Grande do Sul, Brazil, from 2000 to 2004. This qualitative research used a case study approach and content analysis of interviews and documents, besides mapping the activities in relation to the course plan, the relationship between the university and society, and the school's academic output. The results reveal the extension activities practiced by faculty members participating in the study during this period as a space for interaction between faculty, students, and the community in scenarios involving the production and construction of knowledge, contributing to the training of physicians committed to the social reality, as recommended by health curriculum guidelines and specifically those for medicine. The proposed methodology helped shed light on scenarios in which the extension activities take place, as well as on the interaction between extension, undergraduate and graduate studies, and research. 


\section{INTRODUÇÃO}

A extensão universitária é definida no Plano Nacional de Extensão como:

o processo educativo, cultural e científico que articula, amplia, desenvolve e realimenta o ensino e a pesquisa, estabelece a troca de saberes entre a sociedade e a universidade e tem como consequência a produção de conhecimento, propicia a democratização do conhecimento acadêmico e a participação efetiva da comunidade na atuação da universidade.

Envolve a comunidade/sociedade, propicia a reflexão e ação em cenários da realidade nacional e regional, abrange o trabalho interdisciplinar e favorece a visão integrada do social, sendo indissociável do ensino e da pesquisa ${ }^{1}$. Assim, a extensão, como prática realizada por professores em cursos de graduação, propicia a integração de alunos com a comunidade e contribui para o processo de formação de um profissional comprometido com a realidade social.

Quando se pensa na formação da área da saúde, particularmente quando se analisam as Diretrizes Curriculares Nacionais do Curso de Graduação em Medicina² - que propõem a formação de profissionais comprometidos com a realidade social e que esta formação seja integrada aos serviços de saúde desde o início do curso -, concorda-se com Ferreira ${ }^{3}$ em que a interação da universidade com a sociedade assume papel importante, e a extensão, como prática docente, é uma atividade acadêmica que apresenta potencialidade de mudanças na formação dos profissionais da área da saúde.

A formação médica ocorre principalmente na rede assistencial de saúde. E a busca de novos cenários onde a saúde seja mais que a simples manutenção do equilíbrio biológico e em que o futuro profissional aprenda a trabalhar com as comunidades é uma estratégia importante dos programas inovadores para atender às Diretrizes ${ }^{4,5,6}$. Desta forma, as ações de extensão contribuem para formar um médico humanista, crítico e reflexivo, comprometido com o conceito social de saúde. Como discute Melo $\operatorname{Neto}^{7}$ (p. 15), a extensão é "um trabalho social útil sobre a realidade, realizado como processo dialético de teoria e da prática dos sujeitos envolvidos, externando um produto que é o conhecimento novo, cuja produção e aplicabilidade possibilitam o exercício do pensamento crítico e do agir coletivo".

A formação médica e a discussão das contribuições da extensão universitária no processo educativo de um profissional comprometido com a realidade social, com um perfil crítico, reflexivo, com a formação comprometida com a realidade social, propiciam a discussão sobre as ações de extensão realizadas pelos do- centes dos cursos de Medicina. Questiona-se se essas ações favorecem a reformulação do conceito "sala de aula/conteúdo" (aqui, expressa qualquer espaço de ensino de graduação) para uma estrutura dinâmica e ativa de interação entre professor, aluno e sociedade, que ocorre intra e extramuros. São novos cenários? São metodologias ativas de ensino? ${ }^{8}$ Enquanto trabalho acadêmico ${ }^{9}$, a extensão é efetivada na prática docente? É o trabalho e no trabalho de extensão dos professores que se explicita o processo educativo, cultural e científico que objetiva a extensão? Mas como, então, analisar e validar ações de extensão que possam propiciar ao aluno uma visão crítica e reflexiva com vistas à formação de um profissional comprometido com a realidade social?

Este trabalho objetiva desenvolver e aplicar uma metodologia de pesquisa que propicie a análise das ações de extensão com vistas à discussão destas atividades como processo de formação nos cursos de graduação.

\section{MÉTODOS}

Para desenvolver este trabalho, escolheu-se o estudo de caso, que é, na pesquisa qualitativa, o exame detalhado e exaustivo de um ou de alguns objetos, de modo a atingir um conhecimento profundo e amplo da realidade focalizada. Segundo Triviños \& Molina Neto ${ }^{10}$, no âmbito educativo, o estudo de caso pode ser definido como aquele que se ocupa da compreensão de uma ação educativa numa dimensão específica. Poderá ter seu eixo de interesse centrado na própria ação examinada ou no impacto produzido por ela, sempre definindo o âmbito e o contexto focalizados (p. 98-99). Assim, pode-se teorizar a partir da prática, teorizar sobre a prática ou teorizar quanto à transformação desta prática.

Neste estudo, discute-se a extensão universitária como um processo educativo, cultural e científico que viabiliza a ação transformadora da universidade e da sociedade nas trocas de saberes, produzind o o conhecimento e sendo instrumentalizadora do processo dialético entre teoria e prática, levando a uma visão integrada do social, como prática pedagógica realizada por meio de metodologias ativas de ensino.

A metodologia desenvolvida para o delineamento do estudo teve como eixo central o projeto Avaliação Nacional da Extensão Universitária, apresentado pelo Plano Nacional de Extensão Universitária, edição atualizada, Brasil 2000/2001 - Fórum de pró-reitores de extensão das universidades públicas brasileiras e Sesu $/ \mathrm{MEC}^{1}$. 
As dimensões pesquisadas foram de três ordens: plano acadêmico, relação universidade/sociedade e produção acadêmi$\mathrm{ca}^{11,12}$.

Para instrumentalizar a análise das entrevistas e dos documentos em relação ao plano acadêmico, foram criados os seguintes questionamentos: As práticas pedagógicas desenvolvidas nas ações de extensão são metodologias ativas? Como a extensão é vista na faculdade e de que forma é incorporada à vida acadêmica? Representa uma nova instância de formação? Existem relações entre a produção/construção de conhecimento, aprendizagem, diretrizes curriculares e o ensino de graduação, a partir de ações de extensão?

Para analisar o envolvimento das ações de extensão com o plano acadêmico do curso de Medicina, foi desenvolvida uma tabela ${ }^{11}$ para mapear a presença ou não dos seguintes itens: interface com ensino, pesquisa, flexibilização curricular, formas de aprovação, acompanhamento e avaliação das ações; formas de realização quanto aos programas, projetos, cursos, eventos, prestação de serviços, produções e aos produtos acadêmicos; participação do aluno: bolsista, voluntário, validação de créditos, metodologias ativas; ação: interdisciplinar, intersetorial, professores participantes, profissionais participantes; produtos e locais (cenários) das ações.

$\mathrm{Na}$ análise da segunda dimensão, foram criados os seguintes questionamentos: qual população é atendida pelas ações de extensão? Ocorre a apropriação das ações de extensão pela comunidade? Como?

Foi desenvolvida uma tabela ${ }^{11}$ para mapear a presença ou não dos itens que evidenciam a relação universidade/sociedade, tais como:

1. parcerias entre órgãos públicos, privados e movimentos sociais organizados com órgãos privados e com movimentos sociais organizados;

2 população atendida: alunos, profissionais da área, funcionários, comunidade em geral, crianças/adolescentes, familiares, alunos de pós-graduação, profissionais do interior;

3 população atendida participando: do planejamento da ação, do desenvolvimento da ação, da avaliação da ação;

3.1 se existe apropriação: do conhecimento por parte da comunidade atendida (participante da ação), das tecnologias por parte da comunidade atendida (participante da ação), da metodologia por parte da comunidade atendida (participante da ação);

3.2 no curso, se existe o estabelecimento de novas linhas de pesquisa, de uma reorganização curricular, de novos cursos, de novas instâncias de formação decorrentes das atividades de extensão;

3.3 de parcerias: internamente, com departamentos;

3.4 e externamente, com instituições públicas e privadas, com organismos da sociedade civil, com instituições públicas, com instituições privadas e com organismos da sociedade civil.

Para compor a análise da terceira dimensão, foi criada a proposição de evidenciar, como produtos, a produção/construção de conhecimento na discussão da interação que a prática extensionista propicia como cenário de formação.

A pesquisa abrangeu ações de extensão realizadas de 2000 a 2004 na Faculdade de Medicina da Universidade Federal do Rio Grande do Sul (Famed/UFRGS), que estavam registradas no Sistema de Extensão da Universidade Federal do Rio Grande do Sul (SEUFRGS). Os sujeitos da pesquisa foram dez docentes de sete departamentos da Famed/UFRGS, com atividades registradas no SEUFRGS.

Os critérios de escolha destes docentes foram o envolvimento com ações de extensão que contemplassem todas as modalidades de ações, bem como a disponibilidade para ser entrevistado, condição indispensável à seleção dos sujeitos na pesquisa qualitativa. As entrevistas, realizadas no ambiente do trabalho do professor, foram gravadas, transcritas e analisadas de acordo com os questionamentos, nas três dimensões e categorias analíticas acima referidas.

As entrevistas e os documentos referentes às atividades de extensão registradas (propostas e relatórios fornecidos pelo SEUFRGS) foram mapeados em instrumentos criados para cada dimensão e analisados de acordo com o referencial teórico já descrito.

Com esta metodologia foram desenvolvidos instrumentos inéditos, acima caracterizados, para captar informações e analisar as ações de extensão na Famed/UFRGS, preenchendo, desta forma, uma lacuna resultante da inexistência de referências bibliográficas sobre esta temática.

Este artigo apresenta a análise qualitativa de parte dos resultados obtidos com esta metodologia, abrangendo sinteticamente as três dimensões propostas, sem a intenção de esgotar o conjunto das categorias mapeadas, para ressaltar a aplicabilidade do instrumento, numa análise do conteúdo de entrevistas e documentos em diálogo ${ }^{13} \mathrm{com}$ as teorizações existentes.

Esta pesquisa foi aprovada pela Comissão Científica e pela Comissão de Pesquisa e Ética em Saúde, reconhecida pela Comissão Nacional de Ética em Pesquisa (Conep), MS, como Comitê de Ética em Pesquisa do HCPA e pelo Office for Human Rese- 
arch Protections (OHRP) USDHHS, como Institutional Review Board (IRB000921), de acordo com as Diretrizes e Normas Internacionais e Nacionais, em seus aspectos éticos e metodológicos, inclusive quanto ao seu termo de consentimento livre e esclarecido (Projeto 06-213).

\section{RESULTADOS E DISCUSSÃO}

Este trabalho apresenta e discute parte dos resultados obtidos com a metodologia desenvolvida para este fim, mostrando a importância, a pertinência e o ineditismo do tema aqui abordado. Como este trabalho é de natureza qualitativa, os achados de pesquisa estão apresentados no formato de diálogo reflexivo ${ }^{13,14}$.

A primeira dimensão analisada é o plano acadêmico e mostra as possibilidades de incorporação da extensão à prática docente, valorizando as experiências desenvolvidas pelo conjunto de participantes nas ações.

As análises dos documentos e das entrevistas mostram que a maioria das atividades foi desenvolvida com metodologias ativas. Nestas situações, os alunos são sujeitos de sua formação, pesquisando, integrando-se com a comunidade, fazendo discussões. Os participantes do projeto, alunos e comunidade (os pacientes com seus problemas) são "aprendentes" e, ao mesmo tempo, agentes/atores/sujeitos de aprendizagem. Além do estudo dos conteúdos teóricos das disciplinas, ocorre maior envolvimento, bem como a vivência e a integração destes alunos com os pacientes e suas vidas. Ensinar e aprender passam a ser um ato de amor, seja em relação aos conteúdos que possam contribuir para a melhora esperada da doença, seja para aprender e mostrar como age o cidadão consciente de sua condição de sujeito/ator social.

As atividades de extensão pesquisadas ocorreram em Unidades Básicas de Saúde (UBS), escolas, creches e no Hospital de Clínicas de Porto Alegre (HCPA), atuando como espaço de sala de aula expandida privilegiada. Nas atividades desenvolvidas, o aluno é o gestor de seu conhecimento, o que faz crer que a extensão acadêmico-universitária esteja integrada ao ensino e à pesquisa, sendo atribuição da extensão ser pesquisa aplicada, presente na realidade vivenciada, propiciando questões relevantes a serem pesquisadas. Ou seja, é campo fértil de problemas que requerem soluções que levem em conta o conhecimento acumulado na universidade, assim como a reflexão e a discussão de novas questões, isto é, a ampliação do conhecimento, propiciando novos conhecimentos.

Os achados na pesquisa desta dimensão propiciam discussões sobre o processo educacional proposto pelas diretrizes curriculares, o qual, além de formar um profissional com conheci- mentos técnicos, oportuniza ao aluno aprender a conhecer, aprender a fazer, aprender a conviver e aprender a ser. Sem isso, o ensino tradicional, centrado no aprendizado e na transmissão exclusiva do conhecimento do professor, não contemplará a visão social de saúde como integralidade.

Para a formação deste novo profissional, procura-se a prática de metodologias ativas de ensino-aprendizagem, que propõem o ensino baseado na resolução de problemas e a constituição de um aluno/agente de seu aprendizado. Incentiva-se a busca ativa da informação, trabalhos em pequenos grupos, análise crítica das informações, propiciando a construção do conhecimento, a reflexão e a reconstrução das informações.

Nestas práticas, o saber inclui: um saber o quê, um saber como, um saber por quê e um saber para quê. Martins ${ }^{15}$ defende que educar é instrumentalizar para que o indivíduo possa questionar, investigar, compreender, idealizar, transformar e construir. Compreendendo a realidade cultural, social e política, o aluno será um cidadão consciente e comprometido com a construção de uma sociedade mais justa. Portanto, para a formação deste aluno, a educação deve superar as formas tradicionais de ensinar, passando da mera transferência de conteúdos para uma forma integral, propiciando espaço à atuação ativa do aluno, passando a ser o docente um educador-mediador, e a pedagogia entendida como a racionalização e otimização dos processos de aprendizagem.

É o professor quem escolhe o que enfocar nos conteúdos de ensino, pesquisa e extensão. Para este perfil de aluno que se pretende o professor também pode ser um exemplo, um modelo, oportunizando o aprender a ser um aluno cidadão, envolvido com o seu aprendizado e comprometido com a construção da produção social da saúde ${ }^{16}$. O professor não é um transmissor de conhecimento, pois conhecimento não se transmite, ele é produzido, tendo como base informações, que são recebidas e trabalhadas (ação-reflexão), de concepções prévias existentes no sujeito, o que propiciará relações e inter-relações entre os conhecimentos que já tem e os novos que se tornam visíveis. Questiona-se: as ações de extensão propiciam esta reflexão? Em que cenários ocorre e como é feita a reflexão? Utiliza-se metodologia problematizadora? Essas atividades contemplam a extensão como processo educativo, cultural e científico? Articulam, ampliam, desenvolvem, realimentam o ensino e a pesquisa? Tais questionamentos podem ser respondidos por meio do mapeamento dos itens relacionados com o plano acadêmico, utilizando-se o instrumento criado.

O professor, na sua práxis de educador, propicia espaços que possibilitam a aprendizagem, pois - dialogando com Freire ${ }^{17}$ 
considera-se que o motor da aprendizagem é a superação de desafios, a resolução de problemas. A construção do conhecimento novo se dá tomando por base todos os conhecimentos e experiências prévios dos indivíduos.

Neste processo de ensino-aprendizagem, Feuerwerker ${ }^{18}$ define os cenários como "um conceito amplo que diz respeito não somente ao local onde se realizam as práticas, mas também aos sujeitos nelas envolvidos, à natureza e conteúdo do que se faz". Tal conceito inclui aspectos pedagógicos, educativos, morais, emocionais e éticos, que se conformam na interação entre os sujeitos; abrange também os aspectos relacionados aos saberes e práticas, devendo ter-se sempre presentes as reinterpretações do processo saúde-doença à luz da dinâmica social. A mesma autora ainda aponta que "trabalhar na formação médica requer a diversificação de cenários, pois assim o desenvolvimento do processo ensino-aprendizagem acontecerá na realidade social dos serviços de saúde e da comunidade" (p. 16).

A sequência teoria/prática na produção de conhecimento é invertida e assume forma dinâmica por meio da ação-reflexão-ação, que propicia a articulação de vários conteúdos e envolve a interdisciplinaridade, relacionando a saúde na sua integralidade. Isto porque os cenários da vida real são espaços que apresentam problemas que são como fontes a iniciar a produção do conhecimento, e a formação, neste caso, de um médico generalista, humanista, crítico e reflexivamente capacitado a atuar, pautado em princípios éticos, no processo de saúde-doença em seus diferentes níveis de atenção, com ações de promoção da saúde, de prevenção de doenças e de riscos, recuperação e reabilitação à saúde, na perspectiva da integralidade da assistência, com senso de responsabilidade social e compromisso com a cidadania, como promotor da saúde integral do ser humano, conforme Minayo ${ }^{19}$.

A segunda dimensão analisada foi a relação universidade/sociedade, que revela de que modo as atividades de extensão estão presentes na sociedade/comunidade, quais seus pressupostos e finalidades, e como a universidade interage com a sociedade no sentido de transformações recíprocas.

No ensino de Medicina, $\mathrm{o}$ ato de fala ${ }^{20}$ do nono docente entrevistado traz: “Em nossa área, se não existisse essa relação com a sociedade, com os pacientes, com os hospitais, com os ambulatórios, com as unidades de saúde, não daria pra ensinar medicina teórica”. E termina assim: "Essas atividades de enfermaria e ambulatório, se fossem na Engenharia, no Direito, em tudo isso seriam chamadas de extensão, seria trabalho junto com a comunidade, fosse em qualquer outra unidade; então, a extensão pra mim é a universidade na sociedade, isso em todas as áreas, o la- boratório da universidade é a sociedade". A ampliação do espaço da sala de aula para a realidade da comunidade e a vivência de e com problemas reais oferecidos pelas atividades de extensão fazem com que professores e alunos possam questionar informações teóricas e ampliar a articulação entre a teoria e a prática, procurando discutir suas resoluções.

A análise dos dados mostrou ações que envolvem vários segmentos da população, mas, na maioria das vezes, a população atendida foram os próprios alunos da Famed. A extensão realizada pelos docentes da Famed/UFRGS no período pesquisado mostrou forte inserção na graduação e às vezes na pós-graduação, quer resolvendo problemas de disciplinas da pós-graduação, quer auxiliando em pesquisas ou complementando conteúdos de disciplinas da graduação.

A partir de ações de extensão realizadas nos cursos de graduação, podemos analisar as práticas educativas desenvolvidas neste fazer docente em que a universidade interage com a comunidade. Desta maneira, os cenários de ensino são estendidos, e as ações realizadas articulam, ampliam, desenvolvem e realimentam o ensino e a pesquisa como cenários de formação extensionista.

A maior parte da educação médica se dá intramuros e particularmente dentro dos hospitais, embora a maioria dos problemas de saúde ocorra no eixo comunitário (extramuros), local onde poderia ser resolvida grande parte das evidências epidemiológicas, atuando-se sobre a qualidade e o estilo de vida da população, com uma prevenção muito mais eficiente, eficaz e efetiva.

Em pesquisa de Silva ${ }^{21}$ sobre o trabalho acadêmico do professor da Famed/UFRGS, existe a dimensão da assistência/serviço que se articula ao ensino, à pesquisa e à extensão e está ligada à prática médica. Na formação em serviço que ocorre durante o curso de Medicina, a assistência é igual à extensão, ou seja, a extensão universitária como sendo a universidade na sociedade, ação que não deve ocorrer somente no hospital, mas deve integrar a comunidade e a pesquisa.

Das atividades desenvolvidas pelos docentes da Famed/UFRGS em relação ao currículo, concordamos com Malheiros e Guimarães ${ }^{22}$ em que a extensão é a função universitária que melhor articula o compromisso do estudante da área de saúde com a comunidade, promovendo um ambiente de aprendizado adequado. As atividades em extensão proporcionam melhor desenvolvimento do relacionamento e da comunicação entre a equipe de saúde e desta com a comunidade, possibilitando ao acadêmico modular de forma mais efetiva seu estudo, redimensionando a relevância de determinados conteúdos curriculares, 
e adquirir a gama de experiências práticas que os hospitais universitários não podem proporcionar. Ao permitir aos alunos ampliar suas experiências práticas, a extensão preenche a demanda dos acadêmicos por estágios extracurriculares, agora com melhores perspectivas de desenvolvimento do processo ensino-aprendizagem, pois tais estágios se dão, em geral, de forma inadequada e sem supervisão docente.

Este aprendizado baseado na troca e no diálogo é o que propõe a extensão, pois, como defende Paulo Freire ${ }^{13}$, o aprendizado ocorre na educação problematizadora. As ações propiciam a oportunidade de interagir com a comunidade interna (alunos) e a comunidade externa (população, sociedade), com as quais fazemos parcerias. As ações de extensão analisadas incluem a sociedade/comunidade nesta troca dos saberes acadêmico e popular.

Quanto à apropriação do trabalho de extensão pela comunidade, encontramos na pesquisa o seguinte ato de fala, do segundo docente:

é produto que não é validado por nenhum órgão acadêmico, parecendo não ter valor científico, pois não teria impacto, abrangência e relevância - pelo menos aparentemente-, já que não costuma ser citado em nenhum periódico importante da área. É a total falta de apoio e de mensuração da importância do trabalho realizado por esse fazer do professor, que também está produzindo conhecimento, pois a comunidade que participa interage e troca conhecimentos e a solução do problema real das pessoas é buscada, já que, além de solucionar o problema da doença, faz com que a pessoa possa enxergar além da vida sofrida, podendo viver de maneira profilática e digna, mesmo convivendo com a doença.

A terceira dimensão pesquisada, a produção acadêmica, mostra que as ações de extensão realizadas pelos docentes propiciam a produção/construção do conhecimento, pois, como foi evidenciado, elas interagem, criam relações, para o professor, para o aluno e também para a comunidade, dependendo da maneira como é desenvolvida a ação, incluindo as metodologias e os cenários empregados ${ }^{23}$.

O ciclo se reinicia quando, na prática de extensão, ocorre a interação entre professor $/$ sociedade / aluno, na realidade $=$ comunidade $=$ sociedade, abrangendo reflexão e discussão frente a conteúdos teóricos e transformando o Arco de Maguerez ${ }^{14}$ (que mostra a produção do conhecimento tendo como base a realidade) em círculo, onde as etapas observar (refletir), discutir (teorizar), avaliar, aplicar se sucedem como um processo. Aí, então, contempla-se a extensão como processo educacional.
A produção acadêmica é consequência do trabalho docente, que envolve o plano acadêmico, a aprendizagem, a relação com a graduação, a interação universidade-sociedade, levando à produção do conhecimento, e não se restringe à mera produção textual de artigos ou publicação de resumos. A produção/construção de conhecimento como produto do trabalho docente na extensão se explicita nas ações dos profissionais formados como sujeitos críticos, reflexivos, comprometidos socialmente.

A extensão propicia trocas de saberes entre a universidade e a sociedade, sendo instrumentalizadora do processo dialético de teoria e prática, levando a uma visão integrada do social, propondo a formação de um profissional com um novo perfil, em que o paradigma da integralidade e a construção de um novo modelo pedagógico visam a um equilíbrio entre a excelência técnica e a relevância social.

O Plano Nacional de Extensão Universitária do MEC refere que a atividade de extensão terá sentido se interpretada como "a criação e recriação de conhecimentos possibilitadores de transformaç̃oes sociais, onde a questão central será identificar o que deve ser pesquisado e para quais fins e interesses se buscam novos conhecimentos"'7(p. 14).

Assim, o processo ensino-aprendizagem, envolvendo a extensão universitária, se inicia com a situação-problema encontrada no cenário real da sociedade, sendo discutida pelo grupo (docentes, alunos e sociedade) com base em seus conhecimentos e levando a uma busca ativa para suprir as lacunas do conhecimento existente ${ }^{14}$.

Na ampliação dos cenários onde irá ocorrer o aprendizado deste novo profissional haverá trocas importantes do saber acadêmico e dos saberes de outros profissionais da saúde e, principalmente, uma interação com a comunidade, inserindo o grupo na atuação em todos os níveis de atenção primária em saúde e no ciclo de produção/construção do conhecimento ${ }^{11}$.

\section{CONSIDERAÇÕES FINAIS}

Na formação médica, assim como em outras áreas de formação, as práticas docentes têm importante influência no processo de ensino-aprendizagem, em que o estudante aprende a fazer fazendo. No ensino médico, aprender o ofício de médico envolve observar, auxiliar e realizar procedimentos. As atividades realizadas pelo professor não devem envolver somente treinamento e acompanhamento de técnicas. Devem também favorecer o desenvolvimento do aluno, envolvendo-o em vivências que favoreçam a ampliação de seu saber, contribuindo para atender às necessidades da sociedade ${ }^{24}$. Segundo Freire ${ }^{13,17}$, ensinar, aprender e pesquisar envolvem dois momentos do ciclo gnosiológico 
(ciclo do conhecimento): ensinar e aprender o conhecimento já existente e trabalhar a produção do conhecimento ainda não existente.

A extensão produz conhecimento a partir da experiência, que é pouco valorizada na ciência moderna. Neste contexto, a experiência foi silenciada e em seu lugar apareceram os experimentos. Assim, a extensão é vista como atividade secundária no rol das tarefas ilustres da universidade, sendo raramente um critério importante de avaliação do plano de carreira docente ${ }^{25}$ ou do aprendizado do aluno. Mas, neste estudo, a extensão é uma forma de produção/construção de conhecimento por meio da experienci-ação ${ }^{26}$, obtida pela prática extensionista, indissociável do processo ensino-aprendizado, que possibilita a relação sujeito-objeto mediante a problematização (metodologia ativa), suscitando novas questões para pesquisa.

A metodologia proposta para analisar as ações de extensão propiciou conhecer os cenários onde se desenvolvem as atividades e a interação das ações de extensão com a graduação, pós-graduação e pesquisa. A maior parte das ações tem como população-alvo os alunos. A análise das práticas pedagógicas mostrou que a extensão como atividade onde interagem professor-aluno-comunidade é vivida como um espaço de ensino-aprendizagem, sendo uma metodologia ativa, que propicia a produção/construção de conhecimento em diálogo com a realidade. A prática da extensão, como um espaço onde interagiram professor/aluno/comunidade, desenvolvida pelos docentes que participaram do estudo neste período, se fez nos cenários que propiciaram a produção/construção do conhecimento, contribuindo para a formação de um profissional comprometido com a realidade social, como preconizam as diretrizes curriculares da saúde e da medicina em particular.

\section{REFERÊNCIAS}

1. Fórum de pró-reitores de extensão das universidades públicas brasileiras e SESU/MEC. Avaliação Nacional da Extensão Universitária, apresentando o Plano Nacional de Extensão Universitária. Brasília: Atual UESC, 2001.

2. Brasil. Ministério da Educação. Conselho Nacional de Educação. Diretrizes Curriculares Nacionais do Curso de Graduação em Medicina. [on line]. 2001. [acesso em 27 abr. 2008]; Disponível em: http:/www.mec.gov.br/cne/resolucao.shtm\#3.

3. Ferreira NM. A extensão universitária na formação do ensino médico. Boletim Virtual da Associação Brasileira de Associação Médica - ABEM [on line]. 2007; 22. [acesso em
27 abr. 2008]; Disponível em: www.educmed.org.br-publicacoes-boletim virtual.

4. Blasco PG, Gallian DMC, Roncoletta AFT, Moreto G. Cinema para o estudante de Medicina: um recurso afetivo/efetivo na educação humanística. Rev Bras Educ Méd. 2005;29(2):119-128.

5. Sobrinho CLN, Nascimento MA, Carvalho FM. Transformações no trabalho médico. Rev Bras Educ Méd. 2005;29(2):129-135.

6. Amoretti RA. Educação médica diante das necessidades sociais em saúde. Rev Bras Educ Méd. 2005;29(2): 136-146.

7. Melo Neto JF. Extensão universitária e produção do conhecimento. [on line]. Jan-jun, 2003. [acesso em 27 abr. 2008]; Disponível em: http://www.adufpb.org. br/publica/conceitos/09/art_03.pdf.

8. Berbel NA. Problematização e a aprendizagem baseada em problemas: diferentes termos ou diferentes caminhos? Interface Comun Saúde Educ. 1998;2(2)139-154.

9. Búrigo CCD. O trabalho acadêmico do professor universitário no processo de desenvolvimento do espaço público na universidade federal: um estudo de caso na Universidade Federal de Santa Catarina e na Universidade Federal do Rio Grande do Sul. Porto Alegre; 2003. Doutorado [Tese] -Universidade Federal do Rio Grande do Sul.

10. Triviños ANS, Molina Neto V. Pesquisa qualitativa na Educação Física: alternativas metodológicas. Porto Alegre: UFRGS; 2004.

11. Ponte CIRV. Identificação e discussão do processo de produção/construção do conhecimento a partir das ações de extensão realizadas pelos professores da Famed/UFRGS no período 2000-2004. Porto Alegre; 2008. Doutorado [Tese] - Universidade Federal do Rio Grande do Sul, Programa de Pós-Graduação em Cardiologia e Ciências Cardiovasculares.

12. Manfroi WC, Machado CLB, Dorneles MA, Ribeiro EC, Bordin R. Estratégias para a implementação de um projeto de pós-graduação em Educação e Saúde na Faculdade de Medicina da Universidade Federal do Rio Grande do Sul. Rev Bras Educ Med. 2008; 35(1):127-132.

13. Freire P. Pedagogia do oprimido. Rio de Janeiro: Paz e Terra; 1983.

14. Bordenave JD, Pereira AM. Estratégias de ensino-aprendizagem. Rio de Janeiro: Vozes, 1977.

15. Martins JT, Haddad MCL. Um novo olhar sobre a educação. Olho Mágico 2001; 8:15-17. 
16. Gonçalves EL. Pedagogia e didática: relações e aplicações no ensino médico. Rev Bras Educ Méd. 2001;25(1): 20-26.

17. Freire P. Extensão ou comunicação? Rio de Janeiro: Paz e Terra; 1977.

18. Feuerwerker L. Estratégias de mudanças da formação dos profissionais de saúde. Olho mágico. 2002;9:16.

19. Minayo MCS. O desafio do conhecimento: pesquisa qualitativa em saúde. São Paulo: Hucitec; 2006.

20. Habermas J. La logica de las ciencias sociales. Madrid: Tecnos; 1996.

21. Silva MN. Trabalho acadêmico do professor do curso de Medicina: contradições num contexto de mudanças na Famed/UFRGS. Porto Alegre; 2005. Mestrado [Dissertação] - Faculdade de Educação Universidade Federal do Rio Grande do Sul.

22. Malheiros R, Guimarães RGM. Extensão universitária e formação médica: uma análise da experiência dos bolsistas no programa "Escola Cidadã". Rev Bras Educ Med. 1998;22:2-3.

23. Ponte CIRV, Machado CL, Torres M. Extensão universitária como prática pedagógica no enfoque de metodologias ativas. In: Actas de las Segundas Jornadas de Pedagogia Universitária. 2007; San Martin/Argentina: Universidad Nacional de San Martin Argentina; 2007. p. 414.

24. Pimentel M. Relação professor-aluno no ensino médico. In: Machado CLB; Manfroi WC, (Orgs. ). Prática educativa em medicina. Porto Alegre: Dacasa Editora; 2005. p. 168-171.
25. Castro LMC. A universidade, a extensão universitária e a produção de conhecimentos emancipadores. (Ainda existem utopias realistas). - Rio de Janeiro; 2004. Doutorado [Tese] -Universidade Federal do Rio de Janeiro.

26. Machado CLB. Experienci-ação e a formação de educadores. In: XIV Endipe. Encontro Nacional de Didática e Prática de Ensino [CD-ROM]; 2008 abr. 27-30; Porto Alegre: PUC-RS; Unisinos; 2008. p. 12.

\section{CONTRIBUIÇÃO DOS AUTORES}

As autoras Cynthia Izabel Ramos Vivas Ponte e Carmem Lúcia Beera Machado participaram na concepção e desenho deste estudo, coleta, análise, interpretação dos dados e da redação do texto. Marco Antônio Rodrigues participou na concepção deste estudo, análise e interpretação dos dados, da redação do texto. Waldomiro Carlos Manfroi participou na construção, elaboração da escrita e revisão do texto.

\section{CONFLITO DE INTERESSES}

Declarou não haver.

\section{ENDEREÇO PARA CORRESPONDÊNCIA}

Cynthia Isabel Ramos Vivas Ponte

Av. Iguaçu, 176, apt. 202

Petrópolis - Porto Alegre

CEP. 90430-470 RS

E-mail: ponte@cpovo.net 